\title{
Políticas sociales de atención a la dependencia en los Regímenes de Bienestar de la Unión Europea
}

\author{
Gregorio RODRÍGUEZ CABRERO \\ Universidad de Alcalá \\ gregorio.rodriguez@uah.es
}

Recibido: 1-10-11

Aceptado: 19-1-11

\begin{abstract}
RESUMEN
En este trabajo se analizan los cambios sociales que han conducido a la transformación del riesgo de dependencia de riesgo individual y familiar en riesgo social mixto con un creciente papel de las diversas políticas sociales que dan respuesta al riesgo en los distintos regímenes de bienestar de la Unión Europea. Se examina en concreto el modelo general de respuesta al riesgo de pérdida de autonomía como combinación de responsabilidad familiar, individual y social bajo la lógica de una creciente mercantilización y privatización en la provisión de servicios en un contexto en el que los Estados de Bienestar hacen frente a la contención del gasto bajo distintos escenarios de crisis, ajustes y reestructuración. También se indagan las características de los distintos modelos de políticas públicas en el espacio europeo con especial referencia al nuevo modelo español de socialización del riesgo que se pone en aplicación en 2007. En las conclusiones se destaca la complejidad institucional de los modelos o políticas de dependencia, la continuidad y ruptura en las políticas de dependencia y las incertidumbres de su desarrollo en el contexto de reestructuración de los Estados de Bienestar ${ }^{1}$.
\end{abstract}

Palabras clave: dependencia, regímenes de bienestar, globalización mercantilización, cuidados informales, prestaciones sociales, financiación, regulación y gobernanza.

\section{Social policies for care dependency in the European Welfare Regimes}

\begin{abstract}
This article addresses social changes that led to the transformation of individual and family related dependency risk into socially mixed risk with an increasing role for the various social policies which respond to the risk in different welfare systems within the EU. More particularly, the debate is about the general model to respond to the risk of losing autonomy as well as the combination of family, individual and social responsibility on the basis of an increasing commoditization and privatisation in the service provision in the context within which the Welfare State faces cost cutting due to crises, adjustments and restructuring. The features of different public policy models in the EU are also addressed, focussing mainly on the new Spanish model of socialisation
\end{abstract}

\footnotetext{
${ }^{1}$ Ana Arriba, Demetrio Casado, Fernando Casas y Luis Moreno leyeron una primera versión de este trabajo e hicieron comentarios críticos que debo agradecer.
} 
of risk which entered into force in 2007. The institutional complexity of dependency models and policies, the continuation and changes of dependency policies and uncertainties concerning its evolution within the current restructuring of the Welfare State, are underlined in the conclusions.

Keywords: dependency, welfare regimes, globalisation; commoditisation; informal care; social benefits; regulation and governance.

\section{REFERENCIA NORMALIZADA}

Rodríguez Cabrero, G., (2011). Políticas sociales de atención a la dependencia en los regímenes de bienestar de la Unión Europea. Cuadernos de Relaciones Laborales Vol. 29, núm. 1, p. 13-42.

SUMARIO: 1 . La atención a la dependencia como ámbito de las políticas sociales. De la asistencialización a la institucionalización. 2. El modelo general de CLD en el modelo social europeo: génesis, naturaleza y desarrollo. 3. Reformas recientes en las políticas de CLD en los regímenes de bienestar del espacio social europeo. 4. Conclusiones. Bibliografía.

\section{La atención a la dependencia como ámbito de las políticas sociales. De la asistencialización a la institucionalización}

La necesidad de cuidados personales y/o instrumentales de manera relativamente intensa y continua en determinadas etapas de la vida, sobre todo la infancia, la vejez o en situaciones de grave limitación debido a accidentes de diferente tipo, forma parte de las actividades de reproducción de toda sociedad. Hasta recientemente la satisfacción de esta necesidad social ha estado reducida en gran medida al espacio íntimo de los hogares y núcleos familiares; excepcionalmente, la sociedad civil (organizaciones voluntarias u ONG) y el Estado se hacían cargo de los cuidados en ámbitos institucionales (como son las residencias) bajo condiciones de pobreza y ausencia completa de redes familiares. En concreto la acción del Estado era, hasta recientemente, de naturaleza asistencial, si bien los sistemas de Seguridad Social han reconocido la prestación de gran invalidez por causa de accidente de trabajo grave. Obviamente, dentro de este modelo pueden encontrarse variaciones nacionales en función de la articulación entre las esferas del estado, la familia, el mercado y la sociedad civil. Pero, en general, cabe afirmar que hasta principios de la década de los años 70 del siglo XX, en que los modelos nórdicos inician una senda institucional de socialización del riesgo como respuesta a las demandas de la mujer trabajadora (e incluso anticipándose al impacto del envejecimiento), el modelo dominante de cuidados a personas en situación de dependencia era un riesgo familiar y recaía casi en exclusiva sobre la mujer ama de casa que se hacía cargo - aún hoy sigue siendo así - no solo del cuidado de los niños sino también de las personas con discapacidad y personas mayores en situación de dependencia (Bond y Rodríguez Cabrero, 2007). En el análisis de este trabajo se destaca el cambio y la ruptura en las políticas de dependencia pero sin olvidar al mismo tiempo que las continuidades son muy importantes como, por ejemplo, el papel de la Seguridad Social y de las Administraciones regionales y locales en la atención a las situaciones de dependencia. En la práctica los nuevos sistemas de dependencia son formas de expansión, ordenación y racionalización de políticas 
asistenciales previas que, en general, han tendido a configurar un nuevo derecho social.

Situándonos en el período 1950-1980, de expansión del Estado de Bienestar keynesiano-fordista, la división social del trabajo implicaba una asignación de la actividad productiva al hombre y la actividad reproductiva, en su más amplio sentido, a las mujeres. Bajo este modelo el cuidado de las personas en situación de dependencia era, por tanto, familiar y femenino.

A partir de finales de la década de los 70 del pasado siglo se producen cambios profundos económicos, sociales e ideológicos que van a alterar dicha división social del trabajo a los que las políticas sociales van a dar respuesta, y en parte anticipar, creando las condiciones para una nueva división social mediante las políticas de atención a la dependencia o cuidados de larga duración (a partir de aquí CLD). El creciente envejecimiento de la población, cuyo éxito supone también parcialmente el reverso de la dependencia, sobre todo a partir de los 80 años, las transformaciones profundas en el seno de la familia tradicional (en volumen, estructura y roles morales y materiales), y la incorporación de las mujeres al mercado de trabajo, conllevan una crisis profunda del modelo tradicional de CLD de modo que lo que era un riesgo familiar y en mucha menor medida individual y social se transforma ahora en un riesgo social que genera demandas hacia el Estado en pro de una regulación de la respuesta y la asunción de una parte creciente del coste económico del mismo. La respuesta individual será inicialmente débil pero emergerá con relativa fuerza en los últimos años una vez hayan madurado procesos de cambio social, económico e ideológico a los que luego nos referiremos. De hecho, como enseguida trataremos de demostrar, el modelo general de respuesta a la necesidad de atención a las situaciones de dependencia será un conglomerado de prácticas familiares variadas, una intervención extensa del Estado (universalización o cobertura de unas prestaciones básicas para todos los ciudadanos) y una creciente asunción del riesgo por los individuos a través de sus propios recursos (con el apoyo del gasto fiscal del Estado). El peso y combinación de cada nivel de respuesta variará en función del tipo concreto de Estado de Bienestar o régimen de bienestar (Taylor-Gooby, 2004; Bonoli, 2005).

Este proceso de cambio profundo implica, en una primera fase, una transición de la acción protectora del Estado desde modos asistenciales a sistemas universales. Sin embargo, esta extensión del Estado de Bienestar tiene lugar bajo el contexto de su profunda reestructuración, no concluida, en la presente III fase de la reforma social $\left({ }^{2}\right)$ y en el contexto de la globalización neoliberal. La respuesta de los distintos regímenes de bienestar es una combinación específica de sus tradiciones institucionales y culturales (el llamado path-dependency), de las demandas sociales (sobre todo por parte de las mujeres) en favor de una cierta socialización del riesgo y de los constreñimientos financieros e ideológicos de la globalización en los Estados de Bienestar.

${ }^{2}$ La I Fase de la reforma social estaría comprendida aproximadamente entre 1883 y 1950 ; la II Fase entre 1950 y 1990; la III Fase habría tenido su punto de partida en 1990. 
En el caso del modelo social europeo (MSE desde ahora), el desarrollo de políticas y programas de CLD, impulsados por la propia UE desde finales de la década de los 90 del siglo XX y los primeros años de la presente década (Consejo de Europa, 1998; Comisión Europea, 2003), tienen lugar justamente en el entrecruce de la construcción de una Europa competitiva en la economía global y la necesidad de estructurar formas de cohesión social que legitimen los costes sociales del mercado económico y financiero europeo. Pero, como decimos, la respuesta concreta varía entre los distintos regímenes de bienestar (Moreno, 2009; Del Pino, 2009).

Precisamente, por el hecho de que las políticas de CLD emergen en este contexto de reestructuración del Estado de Bienestar, y a pesar de su modesta dimensión en términos de gasto público, se han convertido en cierto modo en campo de tensiones $\mathrm{y}$, también, conflictos latentes entre las fuerzas que sostienen una amplia socialización del riesgo de dependencia y aquellas otras partidarias de mantener la respuesta al riesgo en el ámbito exclusivo de los hogares y, sobre todo, de transferir la responsabilidad del riesgo del ciudadano al individuo. La creación de los quasi-mercados en el seno de los Estados de Bienestar, la externalización de servicios, la tendencia a dar prioridad a las prestaciones monetarias, la libertad de elección, entre otros, son formas concretas que expresan los conflictos latentes en el seno de las instituciones de bienestar entre ideologías encontradas sobre cómo dar respuesta al riesgo social de dependencia. Las distintas políticas sociales que dan respuesta a la dependencia en la actualidad son justamente formas mixtas de socialización, familiarización e individualización del riesgo moduladas por el proceso político.

$\mathrm{Al}$ ser los CLD un ámbito de la política social que da respuesta a necesidades muy personales resulta comprensible esta tensión entre la respuesta pública y la respuesta privada. El éxito de la libertad de elección, que en la práctica se orienta a dar preferencia a las prestaciones monetarias frente a los servicios, defendida por la mayoría de las organizaciones sociales de la discapacidad y de las personas mayores, en coincidencia con el enfoque neoliberal, se puede explicar por la naturaleza propia de los cuidados personales que conlleva la respuesta al riesgo de dependencia. El hecho de que se produzcan consecuencias no previstas en el ejercicio de la libertad de elección, a las que luego nos referiremos, no supone negar el hecho de que ésta forma parte del proceso de asignación de prestaciones en los distintos modelos europeos si bien se establecen limitaciones y controles de cara a garantizar la calidad de la asistencia y la eficiencia de los recursos asignados.

Los CLD, por otra parte, son un ámbito de las políticas sociales favorable a formas de mercantilización y privatización debido, como decimos, a la propia naturaleza del cuidado (con sólidas raíces en el ámbito íntimo), la propia tradición de la provisión de la atención que ha estado bajo responsabilidad de la familia y con el apoyo de organizaciones voluntarias (tercer sector de acción social) y, últimamente, al constituirse los servicios sociales como un espacio de rentabilidad mercantil tanto indirecta (prestación de servicios públicos) como directamente (mediante una oferta propia). En la práctica, como hemos dicho antes, los distintos modelos de CLD son combinaciones específicas de formas de universalización, cuidados informales y provisión privada, no lucrativa y mercantil. 
Para terminar es preciso enfatizar que los CDL (o long-term care en la expresión internacional) son un campo de necesidades sociales y un ámbito de las políticas sociales de cierta complejidad que es preciso tener en cuenta, al menos por tres razones:

a) En primer lugar, porque los cuidados personales se incardinan sobre todo en la esfera privada-familiar que ha visto recargado el tiempo de cuidados de los niños con las personas mayores en situación de dependencia. En realidad los cuidados familiares $\left.{ }^{3}\right)$ constituyen la parte sumergida del iceberg del sistema de cuidados; la acción pública y privada complementan, cual punta del iceberg, el espacio privado-familiar de los CLD que solo bajo situaciones determinadas que lo desbordan (por ejemplo, Alzheimer o demencias cognitivas en su fase terminal) transfiere, sin pérdida de control, la función de los cuidados al sector público o privado. Esto supone que ningún análisis riguroso del problema de los cuidados puede perder de vista esta dimensión de los cuidados informales, como no puede perder de vista la dimensión de género que la ha condicionado históricamente.

b) En segundo lugar, las políticas públicas en el campo de los CLD han sido, y aún lo son, altamente fragmentadas y con bajos niveles de coordinación en un área de naturaleza socio-sanitaria. El Estado ha intervenido tradicionalmente, y de manera residual, desde los servicios sociales (protegiendo a las personas solas y sin recursos en situación de dependencia mediante la atención residencial), desde la Seguridad Social (protección de la invalidez grave originaria o sobrevenida en el trabajo mediante prestaciones monetarias) y, finalmente, desde el sistema sanitario (mediante servicios de rehabilitación o cuidados en instituciones de larga estancia). En la actualidad las políticas públicas se han orientado a dar una respuesta global a la necesidad de CLD mediante una cobertura universal que garantice unas prestaciones básicas y con el objetivo de mejorar la coordinación socio-sanitaria así como la territorial e institucional. Pero las distintas áreas de la política de CLD no desaparecen, por el contrario se hacen más complejas con la superposición del sector privado como colaborador del sector público o como oferta propia. Además, el diseño y puesta en marcha de las políticas de CLD conlleva objetivos más o menos explícitos como son: reducir el gasto sanitario transfiriendo a los servicios sociales parte de los cuidados; reducir la intervención de la Seguridad Social a la gestión de las prestaciones económicas transfiriendo los servicios de residencia y discapacidad al sistema de servicios sociales; distribuir la carga de los CLD entre Administraciones Públicas, sobre todo entre el Estado (regulación y garantía de prestaciones básicas), Comunidades Regiones, Länders, etc- (planificación, gestión y evaluación) y administración local (puerta de entrada en el sistema de CLD y ámbito de gestión de los servicios comunitarios); hacer participe a los ciudadanos de una parte del coste mediante el copago a la

${ }^{3}$ Los cuidados familiares, vecinales y comunitarios suelen denominarse como informales lo que es discutible ya que suelen basarse en formas de organización y compromiso relativamente formales. En este sentido ver Daly (2003). 
vez que favoreciendo la entrada del sector privado en la gestión de servicios. En suma, un espacio altamente complejo de las políticas públicas de CLD en la que se entrecruzan estrategias públicas e intereses privados.

c) La tercera razón explicativa de la complejidad que conlleva el análisis de los CLD es, como hemos dicho antes, que su expansión y racionalización tiene lugar en un marco político-ideológico en el que se confrontan la contención-retroceso del Estado de Bienestar y la creciente mercantilización de los riesgos sociales en el espacio de la globalización (Adelantado y Calderón, 2005; Alonso Benito, 2009). En el caso concreto del MSE dicha confrontación se ha agudizado en la presente década. Si en el período 1980-2000 las presiones del mercado sobre el Estado de Bienestar fueron tentativas y selectivas, en la presente década la presión del mercado, en su más amplia dimensión ideológica y práctica, se ha abierto paso con decisión en demanda de formas de privatización ampliada de servicios y prestaciones públicas así como a favor de una mayor individualización del riesgo y de las condiciones de trabajo en el sector de los servicios colectivos. De este modo las políticas y programas de CLD en el espacio social europeo se desarrollan en un contexto político-ideológico y económico que condiciona su naturaleza institucional, sus objetivos y modos de intervención y gestión del riesgo. La diferenciación social y desigualdades que este nuevo contexto puede generar en los CLD y, en general, en los servicios y prestaciones en que se materializa el Estado de Bienestar, debe ser objeto de análisis en la investigación social.

En este marco complejo de cambios sociodemográficos, económicos e ideológicos, en el que se están desplegando las distintas políticas y programas de CLD, trataremos a continuación de abordar dos aspectos concretos de las mismas:

a) En primer lugar, definir de manera tentativa lo que sería el MSE de CLD como respuesta al riesgo de dependencia, trazando las tendencias generales del mismo y sin considerar en detalle las diferencias nacionales o de los distintos regímenes de bienestar;

b) En segundo lugar, analizaremos los cambios recientes en los distintos modelos de CLD en una parte de los regímenes de bienestar de la UE, considerando su punto de partida y reformas de los últimos años con el fin de poner de manifiesto las distintas combinaciones de Estado, familia, mercado y tercer sector social en la respuesta al riesgo de dependencia; destacaremos el nuevo modelo español de autonomía y dependencia como caso específico del régimen mediterráneo de bienestar como combinación concreta de universalismo, familismo y mercado bajo un sistema de regulación central, con financiación compartida y gestión autonómica y local.

Finalizamos este trabajo con unas breves conclusiones que, además de resumir el análisis precedente, plantearán algunos de los interrogantes que la investigación social y el debate político debe tratar de responder en los años venideros. 


\section{El modelo general de CLD en el modelo social europeo: Génesis, Naturaleza y Desarrollo}

Teniendo en cuenta el complejo contexto general del análisis y comprensión de los CLD - cambios en las prácticas sociales de los cuidados informales familiares, institucionalización contenida del riesgo y superposición de la gestión mercantil en el Estado de Bienestar -, vamos a definir a continuación de manera tentativa lo que podría denominarse como modelo social europeo de CLD. Como todo modelo explicativo lo que pretende es captar las tendencias generales de cambio y transformación de los CDL en el contexto de los cambios que se están produciendo en esta primera fase histórica de la III reforma social en la que los Estados de Bienestar están sometidos a un proceso complejo de contención, recalibración $\left({ }^{4}\right)$ y reestructuración institucional. Dejamos para el siguiente epígrafe un análisis más detallado de los cambios en las políticas de CLD en los distintos regímenes de bienestar que se explican tanto por su historia social e institucional como por los equilibrios sociales y políticos del presente así como por la posición dentro del modelo europeo de globalización.

El modelo general, que hemos esquematizado en el Gráfico 1, establece un marco de análisis a partir del cual es necesario su contraste con cada régimen de bienestar y con cada experiencia nacional concreta.

Es preciso empezar afirmando que las políticas y programas de CLD en el MSE siguen teniendo en los cuidados familiares el núcleo central de referencia, la llamada esfera familiar del régimen de bienestar. En ningún modelo de CLD el Estado sustituye los cuidados familiares. Por el contrario, lo que la casi totalidad de las políticas hace es dar respuesta a la nueva estructura social de los hogares (menor tamaño, nuevos roles, tendencias hacia una relativa desfeminización de los cuidados) bajo un contexto de alargamiento de la esperanza de vida y de políticas de empleo que tienen como objetivo ampliar la participación de la mujer en el mercado de trabajo. En cierto modo, las nuevas políticas de CDLD refuerzan, reconstruyéndolo, el modelo tradicional de cuidados tanto por la vía de las prestaciones monetarias (modelo anglosajón), como mediante servicios y programas de conciliación de la vida familiar y personal con el empleo ( modelo nórdico) o mediante la integración de los cuidadores informales en el sistema de Seguridad Social (modelo continental, caso español) o, como suele suceder con una combinación de todos ellos cuya estructura depende del tipo concreto de régimen y Estado de Bienestar. E incluso las nuevas políticas de CLD reconstruyen el papel histórico de la mujer cuidadora mediante el control y dirección de los cuidados formales o delegados en el seno del hogar a mujeres inmigrantes (Bettio, 2006; Martínez Buján, 2010; Colombo y otros, 2009).

${ }^{4}$ El concepto de recalibración se utiliza aquí en la medida en que ha sido aceptado en el mundo académico europeo de la política social pero es equívoco y de elevada resonancia bélica. Otros términos como adecuación o recomposición interna del Estado de Bienestar se ajustan mejor a la lengua castellana 
A pesar los cambios arriba mencionados en el seno de las estructuras familiares y de la progresiva incorporación de los hombres a las prácticas de los cuidados (caso de los hombres jubilados), la carga de los cuidados sigue recayendo sobre las mujeres que asumen los costes en tiempo y de oportunidad de la carga que en muchos casos son compatibles con una elevada voluntariedad e incluso cierta satisfacción moral (Rogero, 2010). Las políticas públicas solo en escasa medida los compensan y prácticamente no se contabilizan (Durán Heras, 2000). De hecho las nuevas políticas de CLD apenas si reducen la feminización de los cuidados; por el contrario, los reconstruyen y adaptan compensando la carga mediante prestaciones y servicios al mismo tiempo que los desplazan parcialmente hacia los individuos para que compren en el mercado los servicios de cuidados.

En la práctica el modelo tentativo de cuidados familiares se apoya en tres estructuras sociales complementarias: una estructura tradicional de cuidados informales a cargo de la mujer ama de casa y, también, trabajadora; una segunda estructura pública que compensa la carga anterior a cargo del Estado mediante una cierta asalarización doméstica del cuidador informal (integrando en la seguridad social a las/os cuidadores con menos de 65 años) o mediante el apoyo con servicios comunitarios (ayuda a domicilio, teleasistencia y centros de día) o residenciales; por último, una estructura delegada, financiada en parte con prestaciones monetarias, a cargo de mujeres inmigrantes con jornada regular o de veinticuatro horas (regular o irregular). Estructura, ésta última, que diferenciamos por su importancia pero que en la práctica forma parte de las dos anteriores. Mediante esta jerarquía complementaria de cuidados se produce una cierta refamiliarización del sistema tradicional en la que no se evita ni la doble jornada ni el predominio de la feminización de la carga de cuidados. Solo una profunda división social de género, apenas desarrollada, podrá alterar esta reconstrucción basada en un complejo entramado cultural y de compromisos morales.

En consecuencia nuestra tesis es que en el conjunto de los regímenes de bienestar europeos se está produciendo una reconstrucción del sistema de cuidados familiares a personas dependientes que se basa en sólidas tradiciones culturales, en el propio diseño de las políticas públicas y en la concepción conservadora de la libertad de elección entre prestaciones sociales. De este modo la mujer - ama de casa, trabajadora nativa o trabajadora inmigrante - sigue asumiendo el mayor peso de la carga. Las políticas públicas lo que hacen es compensar parcialmente la carga y, en situaciones muy determinadas, asumirlas en su totalidad bajo control familiar.

Los cambios habidos en los últimos veinte años en la esfera estatal de CLD son el cambio más relevante acaecido en el conjunto del sistema de cuidados. Las políticas públicas daban una respuesta residual, asistencial, a las necesidades que generaba la discapacidad y la dependencia. Bajo el Estado de Bienestar keynesiano existía una clara división en lo tocante a los cuidados de personas dependientes. El ama de casa se hacía cargo del grueso de los cuidados y el Estado compensaba en los casos de máxima gravedad y soledad. Además el amplio volumen de mujeres cuidadoras y la sólida moral de obligación familiar (femenina) de los cuidados en el seno de los hogares no planteaba ninguna necesidad de cambio en las políticas públicas. Los factores culturales modulaban esta obligación de modo que en el mundo anglosajón y 
nórdico el compromiso familiar de los cuidados era, y aún es así, sustituido por la asunción del riesgo por el individuo o por el Estado sin eliminar nunca la responsabilidad y la carga familiar. En los regímenes de bienestar continentales y, sobre todo, en el mundo de la Europa del Sur, la obligación familiar es amplia e intensa hasta el punto de que los políticas de CLD han respetado y reforzado este modelo haciéndolo compatible con la inserción laboral de la mujer.

En la década de los 70 del pasado siglo se abrieron paso en el mundo nórdico formas de socialización del riesgo de dependencia, no explícitas, sino mediante la extensión de los servicios sociales en el ámbito municipal. Ello era consecuencia de la creciente integración de la mujer en el mercado de trabajo, de la aceleración del envejecimiento de la población y de la acción favorable de las políticas públicas. Bajo este primer modelo tentativo, sin leyes de dependencia que los desarrollaran, la provisión de servicios estaba a cargo del Estado directamente mientras que la familia controlaba el proceso de asignación y provisión de servicios. Esta extensión de facto de los servicios sociales a las situaciones de dependencia primero se hizo bajo un modelo de tipo residencial y, posteriormente, a medida que las personas afectadas fueron explicitando su apoyo a vivir en casa hasta donde fuera posible, bajo modelos comunitarios de atención que, además, suponían un menor coste inicial. Parte del colectivo de mujeres cuidadoras informales se convirtió en mujeres cuidadoras en el sistema de servicios sociales.

Pero es en los inicios de la década de los años 90 del pasado siglo cuando las políticas de CLD pasan a formar parte de la agenda política orientadas a la socialización del riesgo transformando los modelos asistenciales en modelos de cobertura universal. La confluencia de los factores antes mencionados - aceleración del proceso de envejecimiento de la población e incremento de las discapacidades en las edades elevadas (Abellán y Esparza, 2006), inserción laboral de la mujer y cambios en las estructuras familiares -, generaron un creciente debate político y científico sobre la necesidad de avanzar hacia políticas de socialización del riesgo. Las asociaciones cívicas y de acción social de la discapacidad y de personas mayores presionaron en dicha dirección (en el caso de España la LISMI de 1982 fue en parte resultado de esta movilización). También hay que tener en cuenta las demandas de asociaciones de mujeres y profesionales de los servicios sociales y de la gerontología y geriatría. En el mundo continental la política pionera de Austria en 1993 de desarrollar una ley de cobertura universal de las situaciones de dependencia en el marco de la Seguridad Social inicia una senda de desarrollo de leyes que, superando el limitado enfoque asistencial, definen y aprueban modelos caracterizados en general por cuatro rasgos: reconocimiento del derecho subjetivo a la protección universal en base a un baremo de valoración de la dependencia en grados de severidad; combinación de prestaciones monetarias y servicios sociales con amplio margen de elección; financiación mixta con impuestos, cotizaciones sociales y copago; y un sistema de responsabilidad institucional compartido por diferentes niveles territoriales de gobierno y participado por agentes sociales, empresarios y organizaciones sociales.

Pero las nuevas políticas de institucionalización del riesgo ni venían a sustituir a la familia ni podían ser de amplia intensidad protectora sino que se centraban en organi- 
zar los sistemas existentes, racionalizarlos y reforzarlos con una cobertura pública básica, no ilimitada. En el marco institucional del MSE de CLD ello suponía que las políticas sociales, entre ellas las de dependencia, es decir, las políticas de cohesión, debían ajustar sus objetivos y medios a los requerimientos de la competitividad (la idea de que las políticas sociales deben ser productivas), lo que suponía en el caso de la última rama de política social en alcanzar una institucionalización del riesgo de dependencia bajo la cual los CLD estarán sometidos a tres restricciones: no sustituir la responsabilidad familiar (sino reforzarla), trasladar parte del riesgo al individuo (responsabilidad individual a la que se hace frente mediante la previsión social) y, finalmente, abrir la puerta a la gestión privada de servicios sociales. Estas restricciones no son nuevas, se pueden detectar en las políticas sociales previas. Lo que sucede ahora es que alcanzan fuerza institucional y delimitan el alcance, intensidad y modo de provisión de los CLD.

Esta triple restricción supone aplicar políticas sociales que, en lo institucional, recalibran al Estado de Bienestar produciendo desplazamientos de programas y gastos entre el sistema de servicios sociales, el sistema sanitario y la Seguridad Social; en el plano económico-financiero se desarrollan las nuevas políticas bajo fórmulas de contención del gasto social (nuevas combinaciones de amplia cobertura con una limitada intensidad protectora) y apertura al mercado de la gestión de los servicios públicos (que a su vez desplaza al tradicional colaborador del Estado, el Tercer Sector de Acción Social); y, finalmente, en el plano político-ideológico se construye y refuerza la idea de que el riesgo de dependencia es un riesgo privado compartido en cuya respuesta la familia ocupa el lugar central, el Estado garantiza unas prestaciones básicas y el individuo debe asumir una carga creciente de responsabilidad como contrapartida de la libertad de elección. Se trata de una combinación asimétrica de riesgos que combinan socialización, familiarización e individualización jerarquizados por la posición de clase social. El primer riesgo tiende a contenerse, el segundo a reconstruirse y el tercero a expandirse. Cada régimen de bienestar establece su combinación específica.

En cuanto materialización de la transformación de un derecho residual en un derecho subjetivo el Estado regula a nivel general la valoración de la dependencia y garantiza unas prestaciones básicas; es el mínimo necesario para garantizar una igualdad en el territorio de un Estado. Su financiación es compartida por los tres niveles de gobierno y por los usuarios en función de la renta, produciéndose en general un desplazamiento de la carga financiera y de la gestión al ámbito local que no siempre, excepto en el mundo nórdico, tiene capacidad para asumirla. El estímulo de la oferta privada de aseguramiento se produce mediante la extensión de las desgravaciones fiscales. Todo ello tiene lugar bajo el predominio de políticas de rebajas fiscales que contribuyen a frenar la acción pública directa y a estimular la provisión privada. 


\section{Gráfico 1}

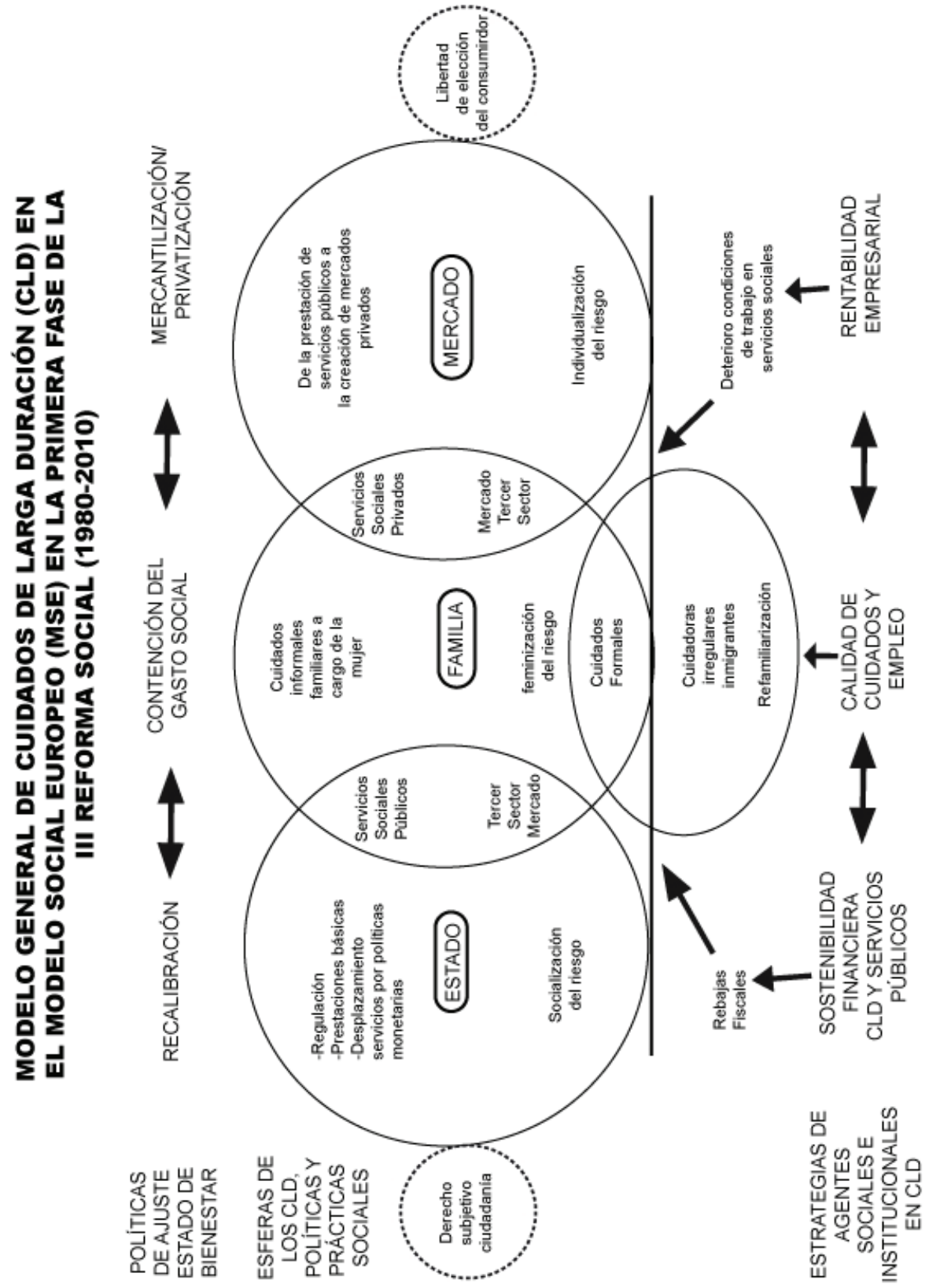

Fuente: Elaboración propia 
La esfera privada mercantil ha ocupado hasta recientemente una posición marginal en los servicios sociales a diferencia del sector sanitario y educativo. El modelo dominante de provisión de servicios previamente a la década de los ochenta del pasado siglo era la de gestión directa por parte del sector público o en colaboración con el Tercer Sector. Los procesos de reestructuración del Estado de Bienestar, acelerados después de 1989, han ampliado el sector mercantil en la rama de los servicios sociales mediante la concertación de servicios y la contratación en pie de igualdad con el Tercer Sector. La contracción relativa del Tercer Sector varía entre países y sectores. Así, por ejemplo, en el caso español el sector de organizaciones de personas con discapacidad sigue teniendo un peso relevante en la gestión de servicios mientras que el sector de organizaciones de la tercera edad apenas si tiene presencia en la gestión de servicios reduciendo sus actividades a la reivindicación, representación y promoción de las personas mayores. Por otra parte el papel de Caritas y Cruz Roja, Fundosa o Lares siguen teniendo un papel relevante en la gestión de servicios públi$\cos$ y propios. Este proceso es lo que se conoce como mercantilización. Reducir costes, crear mercados internos y gestionar el sector público mediante fórmulas empresariales son elementos todos ellos de la expansión de lo que antes denominamos como nueva administración pública. Como consecuencia de estos cambios se produce un desplazamiento del empleo del sector público al sector privado que se convierte en mayoritario en las dos últimas décadas. Un desplazamiento que se justifica no solo por razones de contención del coste sino como forma de facilitar la libertad de elección entre proveedores a las clases medias consumidoras que buscan diferencia en el producto y que supuestamente puede ofrecer en mayor medida el sector mercantil. La calidad y la libertad de elección (Lundsgaard, 2005), objetivos fundamentales para cualquier Estado de Bienestar, se convierten al mismo tiempo en fetiches ideológicos a través de los cuales un servicio público se trastoca en mercancía. En muchos sentidos, la satisfacción de la necesidad de CLD se segmenta en función del acceso a la oferta de servicios públicos y privados. El precio y el beneficio condicionan la oferta y la supuesta diferencia de calidad entre el sector público (supuesta baja calidad) y el sector privado (supuesta elevada calidad) pasa a formar parte del entramado ideológico discursivo como si de un dogma se tratara.

El desarrollo de los CLD en la presente década nos muestra cómo se ha producido un giro desde la extensión mercantil hacia formas de privatización ampliada. Si en el caso de la primera la oferta es pública y la gestión privada, la privatización supone una profundización de la anterior ya que se trata de la creación de una oferta privada propia que se ofrece en contrato al sector público o a los consumidores que estén dispuestos a pagar un precio por ella. Es decir, la presencia del sector mercantil en los CLD en la década de los 90 se justifica en la contención del Estado de Bienestar y en la ganancia de eficiencia; ahora se trata de consolidar la oferta mercantil justificada en una demanda social que encuentra en la plena libertad de elección su filosofía justificativa.

Es decir, una vez que el sector mercantil, superpuesto en el sector público, se naturaliza y alcanza un nivel determinado de desarrollo, queda encajado en el entramado institucional del Estado del Bienestar. Descartada la resistencia a su expansión queda 
abierta la puerta a formas variadas de privatización que segmentan la sociedad a partir de una oferta privada no siempre competitiva y de naturaleza oligopólica. Esta extensión del sector mercantil a partir de la gestión de los servicios públicos y de la demanda de segmentos de elevada renta de la esfera familiar se ve reforzada por dos formas de desplazamiento del riesgo hacia la esfera y familiar:

- En primer lugar, los colectivos sociales de bajos ingresos y hogares con mujeres al margen del mercado de trabajo se hacen cargo del coste del cuidado, sobre todo en tiempo y costes de oportunidad. La contención del coste público se compensa a costa del coste privado. La mayor visibilidad del coste de cuidados no pagados de la mujer e, incluso, la compensación parcial de aquél por las prestaciones sociales, no puede ocultar la diferenciación de clase que se produce en los CLD. En el caso de las capas medias tienen que recurrir además a los ahorros o a la liquidación del patrimonio para hacer frente al coste de los cuidados.

- En segundo lugar, en los grupos de renta media-alta y alta la provisión de los CLD se produce mediante el recurso al mercado en el que compran servicios y productos que suelen conllevar aparejados desgravaciones fiscales.

La segmentación en los CLD, como en otras áreas del Estado de Bienestar, tiende a reforzar esquemas duales de protección que aumentan la desigualdad social y tienden a minar la legitimación del sistema público. La coyuntura actual de crisis económica y financiera favorece la profundización de esta formas de privatización que se presentan como reformas inevitables y que en el caso de los CLD tiende a contener el gasto público y a estimular la demanda de la oferta privada.

De lo anteriormente dicho se plantea un conjunto de interrogantes a los que la investigación social debe dar respuesta en los años venideros y que, sin duda, serán objeto de debate social y político. Nos referimos a los siguientes: los efectos que tendrá en la oferta de servicios sociales cierta contracción del Tercer Sector a favor del sector mercantil con el que no siempre puede competir en precios; las consecuencias de la transformación parcial de los cuidados personales en mercancía y como afectará a la calidad de los servicios; en qué medida la inevitable concentración empresarial de la oferta de servicios privados no se traducirá en mayores costes; finalmente, cómo la extensión de los mercados privados de servicios afectará a la calidad de las condiciones de trabajo sin las cuales no es posible un cuidado de calidad.

\section{Reformas recientes en las políticas de CLD en los regímenes de bienestar del espacio social europeo}

La respuesta de los regímenes de bienestar de la UE a la necesidad de atender la dependencia tiene lugar en un momento histórico de la reforma social cuando los distintos regímenes de bienestar (Ferrera y Rodhes, 2000) se encuentran en una encrucijada como consecuencia de tres procesos confluyentes en el tiempo: una 
globalización neoliberal que favorece formas de mercantilización y privatización de la acción protectora que tienden a trasladar al individuo un creciente coste de los riesgos sociales; políticas europeas que estimulan políticas sociales en las que la protección social sea productiva y se articule con la lógica de la competitividad, lo que viene exigiendo profundas reestructuraciones en la estructura y dinámica de los Estados de Bienestar; y, finalmente, variadas tendencias en las políticas nacionales de dependencia en las que la respuesta al riesgo a nivel nacional tiene lugar en contextos institucionales de profunda descentralización, un intenso proceso de envejecimiento de la población y nuevas formas de división social del trabajo de cuidados en el seno de los hogares.

\section{A) Tendencias de cambio en las políticas de CLD entre 1990 y 2010}

Una primera aproximación a los procesos de reforma de los CLD, y enlazando con el epígrafe anterior, nos obliga a poner de manifiesto los cambios que han tenido lugar en las distintas reformas en las dos últimas décadas. Se constata con claridad que en lo referente a los CLD se han dado continuidades y cambios, tal como hemos esquematizado en el CUADRO 1.

Son continuidades: los avances en la socialización del riesgo no solo en los distintos países que componen el régimen de bienestar continental (Austria, Alemania, Francia, Luxemburgo, Bélgica), sino incluso en países de la Europa del Sur (caso de España desde 2006); la expansión de la red de servicios públicos y privados; la consolidación de un modelo de cuidados orientados a apoyar a las personas en su casa frente al modelo de tipo residencial; modos de valoración de la dependencia muy parecidos (en grados y niveles) y realizados por profesionales del ámbito sociosanitario, diferenciados de la asignación de prestaciones sociales que realizan los profesionales de los servicios sociales; modelos de financiación mixta; y constitución de los CLD como política social relevante en la UE junto a los sistemas de pensiones y el sistema sanitario en el marco de las propuestas de modernización de la protección social.

Pero se han producido discontinuidades en la presente década como son las políticas de contención del gasto social en CLD; una mayor preferencia de las prestaciones monetarias respecto de los servicios; una cierta refamiliarización de las políticas; un avance del proceso de privatización mediante la expansión de la oferta privada mercantil; un retroceso relativo del Tercer Sector; y una tendencia a concentrar la atención en el grado de dependencia más grave. Es decir, se ha producido un giro en las políticas de CLD. No se trata de un giro drástico, sino de reformas parciales que profundizan tendencias previas, como luego veremos. La mercantilización de servicios o la libertad de elección no son prácticas de la presente década, surgieron dos décadas antes y ahora han madurado de forma muy específica bajo condiciones económicas y político-ideológicas muy determinadas, es decir, bajo el predominio de políticas neoliberales en materia de política social que han hecho una interpretación y aplicación muy determinadas de prácticas institucionales ya existentes como son la externalización de servicios y la libertad de elección del ciudadano. La externalización es un medio de gestión que no necesariamente tiene que tener una orientación 
mercantil al igual que la libertad de elección no implica una práctica orientada en exclusiva al mercado. La propia liberalización de los servicios promovida por la UE y las tensiones que ello genera en el desarrollo de los servicios esenciales, entre ellos los servicios sociales, nos ofrece una idea del problema que analizamos (Casas Mínguez, 2010).

\section{Cuadro 1}

\section{Tendencias de cambio en las políticas de CLD entre 1990 Y 2010}

\begin{tabular}{|c|c|c|c|c|c|c|c|}
\hline Período & $\begin{array}{l}\text { Fase de } \\
\text { desarrollo }\end{array}$ & $\begin{array}{l}\text { Naturaleza del } \\
\text { riesgo }\end{array}$ & $\begin{array}{l}\text { Población a } \\
\text { proteger }\end{array}$ & $\begin{array}{l}\text { Asignación de } \\
\text { prestaciones }\end{array}$ & $\begin{array}{l}\text { Tipología } \\
\text { dominante } \\
\text { de presta- } \\
\text { ciones }\end{array}$ & $\begin{array}{l}\text { Provisión de } \\
\text { servicios }\end{array}$ & Financiación \\
\hline $1990-2000$ & $\begin{array}{l}\text { Expansión } \\
\text { de los } \\
\text { CLD }\end{array}$ & Socialización & $\begin{array}{l}\text { Personas en } \\
\text { situación de } \\
\text { dependencia }\end{array}$ & $\begin{array}{l}\text { Condicionada } \\
\text { hacia los } \\
\text { servicios }\end{array}$ & Servicios & $\begin{array}{l}\text { Mixta: } \\
\text { sector } \\
\text { público y } \\
\text { tercer sector }\end{array}$ & $\begin{array}{l}\text { Mixta: } \\
\text { impuestos y } \\
\text { copago }\end{array}$ \\
\hline $2001-2010$ & $\begin{array}{l}\text { Racionali- } \\
\text { zación y } \\
\text { contención } \\
\text { del coste }\end{array}$ & $\begin{array}{l}\text { Mixta: refamilia- } \\
\text { rización e } \\
\text { individualización }\end{array}$ & $\begin{array}{l}\text { Tendencia a } \\
\text { proteger las } \\
\text { discapacidades } \\
\text { más graves }\end{array}$ & $\begin{array}{l}\text { Libertad de } \\
\text { elección } \\
\text { condicionada }\end{array}$ & $\begin{array}{l}\text { Prestacio- } \\
\text { nes } \\
\text { monetarias } \\
\text { (presupues- } \\
\text { to personal }\end{array}$ & $\begin{array}{l}\text { Privada: } \\
\text { tercer sector } \\
\text { y, sobre } \\
\text { todo, sector } \\
\text { mercantil }\end{array}$ & $\begin{array}{l}\text { Mixta: } \\
\text { impuestos, } \\
\text { copago y } \\
\text { desgravacio- } \\
\text { nes fiscales }\end{array}$ \\
\hline
\end{tabular}

Fuente: elaboración propia

Estas tendencias de cambio, aceleradas desde 2005 hasta la actualidad (Lundsgaard, 2005; OECD, 2005; Pacolet, 2006; Pavolini y Ranci, 2008), seguramente se profundizarán bajo el impulso de las reformas exigidas por los mercados financieros para extender el espacio mercantil y sustituir al Estado de Bienestar allí donde las necesidades se pueden convertir en mercancías. Pero esta tendencia no es inexorable dadas las inercias institucionales, los problemas de legitimación política que provoca y las propias exigencias de cohesión social que requiere una ampliación del capital financiero. Las resistencias y conflictos sociales forman parte de este proceso de cambio. El devenir de los CLD como política pública dependerá en muchos sentidos de lo que suceda en el conjunto del Estado de Bienestar y, sobre todo, en el sistema de pensiones y de sanidad, de cuyo conglomerado forma parte. Si el desarrollo de los CLD debe caminar bajo los principios de universalización, calidad y sostenibilidad financiera, según la doctrina europea, el análisis precedente nos muestra que tal desarrollo está lleno de problemas y contradicciones que se resolverán en la arena política.

Una vez trazadas las tendencias generales de cambio en las políticas de CLD analizamos a continuación de manera sintética los cambios más relevantes que han tenido lugar en los distintos regímenes de bienestar 


\section{B) Cambios en las politicas de CLD en los regímenes de bienestar europeos. Una visión general.}

En trabajos precedentes (Rodríguez Cabrero, 2005 y 2009; Sotelo, 2007; Arriba y Moreno, 2009) hemos analizado la naturaleza y características generales de los sistemas de CLD en la UE. Aquí nos concentraremos en los países miembros de la UE antes de la ampliación de Mayo de 2004, es decir, a la UE-15. Esto se justifica en que aún no disponemos de suficiente literatura para analizar los nuevos regímenes de bienestar (báltico, del este, sur de Europa), que no pueden ser asimilados a los regímenes clásicos sin forzar la realidad. En el CUADRO 2 se recogen las características básicas de los sistemas de CLD diferenciando entre el período 1980-2000 y desde 2000 hasta la actualidad. No se trata obviamente de una periodificación exacta sino aproximada.

Siguiendo la clasificación seminal de Esping-Andersen (1990), ampliada a la Europa del Sur hemos diferenciado cuatro regímenes ideales de bienestar y en cada uno de ellos destacamos sus rasgos más específicos con el fin de concretar el modelo general en el plano real.

1. El modelo nórdico, donde se suelen incluir, además de los países del norte de Europa Los Países Bajos -como modelo que comparte rasgos de los modelos nórdico y continental -, construyó desde finales de la década de los 70 del pasado siglo un sistema de cobertura universal, financiado con impuestos, basado sobre todo en servicios sociales provistos por los municipios. Este modelo ha afrontado cambios relevantes con la llega al gobierno de partidos conservadores desde finales de la década de los 90. Los cambios - ampliación del mercado en el sistema de CDL -, no han sido radicales sino lentos y mediante superposición de las reformas en el sistema tradicional que, ya en los primeros años 90, estaban siendo introducidos parcialmente por gobiernos socialdemócratas siguiendo las tendencias generales de contención del gasto social y de reestructuración del Estado de Bienestar, de modo que la externalización parcial de los servicios sociales y la promoción de la competencia entre proveedores empezaban a formar parte de la gestión de los CLD. A su vez, como decimos, las reformas de la presente década no sustituyen el modelo público sino que lo reforman mediante encajes o empotrados organizativos flexibles que favorecen al mismo tiempo más mercado y más familia (el caso danés es una excepción en cuanto a los cuidados familiares ya que por su tradición es residual) a la vez que dan respuesta a las expectativas de grupos de renta elevada que aspiran a mejoras diferenciales de calidad en la atención.

De este modo se produce un tránsito silencioso desde el modelo histórico netamente público (Sipilä, 1997) a otro modelo crecientemente mixto (Blomquist, 2004; Huber y otros, 2005 y 2009) que combina los sistemas público y privado mediante superposición empotrada del segundo en el primero, a modo de esqueje organizativo llamado a generar nuevas formas de gestión mixta. Este modelo, siguiendo las tendencias europeas se basa en la externalización de la gestión de servicios y en una creciente apuesta por la libre elección del consumidor de los servicios públicos en competencia y de nuevos productos basados en desgravaciones fiscales. 
Esta estrategia de expansión complementaria del sector mercantil, sin desmantelamiento del sistema público, se confirma en el conjunto de los países del régimen nórdico de bienestar (Dahl, 2005). También se confirma esta tendencia en el caso danés en el cual el sector público sigue conservando un importante peso relativo (Rostgaard, 2006) a pesar de la extensión del sector mercantil en el sistema de servicios sociales y de la importancia de la libertad de elección como principio orientador de la asignación de prestaciones sociales. La financiación es pública, estatal y municipal, orientada a los servicios comunitarios. La libertad de elección se introduce en la primera mitad de la presente década tanto entre proveedores como entre tipos de servicios con el fin de ir creando una corresponsabilidad entre el Estado y el ciudadano. Esta libertad de elección ya existía en otros ámbitos del Estado de Bienestar y se ha extendido al sistema de los servicios sociales con el apoyo de las organizaciones de la discapacidad y tercera edad y el rechazo sindical y de los partidos de izquierda. Ahora bien es preciso aclarar que la libertad de elección está condicionada por el control de los proveedores y el propio ejercicio de la misma que tiene límites precisos.

En el caso holandés encontramos una de las reformas más intensas en el sistema de CLD. Surgieron en el sistema sanitario como gastos excepcionales (el AWBZ) en 1968 y con una clara orientación residencial. Este sistema ha sufrido dos reformas: una primera reforma tiene lugar en 1995 con la introducción del presupuesto personal (personal budget) que abre la vía a las prestaciones monetarias como el chequeservicio y como compensación al cuidador no profesional lo que permitía dar satisfacción al consumidor de clase media a la vez que reducir los costes unitarios del sistema. La segunda reforma es de 2006 en la que el modelo de CLD entra en una fase de contención de costes y de clara orientación al mercado. Paralelamente el sistema de des-institucionaliza en favor de los cuidados domiciliarios, se generan mercados internos (es decir, sistemas de competencia interna en el sector público) y se extiende el copago al servicio de ayuda a domicilio. La ley de atención social de 2007 consolida estas tendencias de contención de costes transfiriendo el servicio de ayuda a domicilio (que estaba en el sistema sanitario) a los servicios sociales municipales lo que provoca, junto a mejoras de accesibilidad de los servicios, un grado de discrecionalidad que no tenía, una menor intensidad horaria y costes salariales inferiores a los existentes en el sistema sanitario (Shut y Van den Berg, 2010).

2. El modelo anglosajón, en este caso nos referimos al Reino Unido en exclusiva, no ha sufrido reformas importantes en cuanto a CLD. Se podría afirmar que se trata de un sólido sistema asistencial desde el que se han intentado repetidas reformas para su transformación en un sistema de cobertura universal en línea con los modelos nórdico, continental o español.

El modelo británico es un modelo dual en el que la protección sanitaria es universal y los CLD tienen una naturaleza asistencial. El sistema de CDL se basa en dos pilares: un primer pilar está constituido por las prestaciones monetarias que financia la Seguridad Social para personas mayores dependientes (attendance allowance), personas con discapacidad (disability living allowance) y ayudas a los cuidadores familiares (care allowance), en todos los casos bajo demostración de bajos ingresos. Es decir, es un pilar asistencial. Por otra parte, existe un pilar de servicios sociales de 
tipo asistencial, a cargo de los ayuntamientos, al que pueden acceder todos los ciudadanos y que conlleva el copago en función de la renta.

Este modelo, extenso en servicios por otra parte, ha acometido varias reformas en los últimos años, casi todas ellas dirigidas a extender la mercantilización en el sistema: externalización de los servicios así como a sustituir la prestación de servicios por las prestaciones monetarias, sobre todo bajo la forma del presupuesto personal. La reforma de 1993 (Means, Morbey y Smith, 2002) encamina el sistema hacia la consolidación de un sistema asistencial contenido de CLD, dirigido sobre todo a personas con grave dependencia y sin recursos, a la vez que fomenta la creación de un sistema de seguros privados basado en desgravaciones fiscales. El personal budget se consolida así como la extensión de los seguros privados. La narrativa del consumerismo se extiende entre las capas medias de la población desde la segunda mitad de los años 80 hasta la actualidad; se trata de una maduración bajo el laborismo de las prácticas institucionales desarrolladas los gobiernos de Thatcher y Major.

Por otra parte los intentos de poner en marcha un sistema de cobertura universal a partir de los trabajos de la Royal Comisión sobre CDL en 1999, así como intentos posteriores hasta llegar a 2009 (Green Paper sobre LTC) van a fracasar una y otra vez. Las políticas de CLD continúan bajo un modelo asistencial ampliado en el que, por su misma naturaleza, se va a empotrar en el sector público un sólido sistema de oferta mercantil actualmente en fase de expansión. La tradición histórica asistencial de los servicios sociales en el régimen anglosajón reforzada por las ideologías del consumerismo y las políticas neoliberales seguramente acrecerán un espacio mercantil ampliado en CLD.

3. El modelo continental de CLD comprende un conjunto de países que en las dos últimas décadas han puesto en marcha sistemas de cobertura universal con el fin de reforzar y, en su caso, sustituir un sistema tradicional de cuidados a personas en situación de dependencia. En general estos modelos se han desarrollado en dos fases: una fase de expansión basada en la universalización del derecho subjetivo a la acción protectora que garantiza unas prestaciones básicas y una segunda fase de contención, reequilibrio interno y apertura a formas de mercantilización y de libre elección. De manera sucinta destacamos algunos de estos cambios en base a tres países que nos confirman este doble proceso de cambio: Austria, Alemania y Francia. Todos ellos, surgidos en sistemas de Seguridad Social bismarkianos, tienen como filosofía fundamental de los CLD que los cuidados pertenecen al ámbito de la familia, quien tiene la responsabilidad de los mismos. El envejecimiento de la población y la incorporación de la mujer al mercado de trabajo requerían una extensión de los cuidados asistenciales hasta un plano universal con el fin de conciliar cuidados familiares, empleo de la mujer y envejecimiento.

Austria es el primer país del régimen continental que aprueba una ley de dependencia en 1993 que transforma el modelo asistencial en otro de cobertura universal. Como el modelo alemán los CLD pertenecen a la familia y sólo en determinados casos la asistencia asocial se hacía cargo de los cuidados; los servicios eran gestionados normalmente por organizaciones voluntarias y religiosas, además del Estado. Este modelo residual se transforma en 1993 en dos ramas de protección: la primera no 
genera un derecho subjetivo, es la rama tradicional de servicios sociales asistenciales (financiados con impuestos generales), que sigue vigente, bajo control de las provincias y una nueva rama de protección universal, federal, que genera derecho subjetivo, bajo la Seguridad Social, cuyas prestaciones son monetarias (financiadas con cotizaciones sociales). El acceso depende de la valoración del grado de dependencia (7 grados).

De este modo se articula un modelo de responsabilidades compartidas entre niveles de gobierno (central y provincial) y entre esferas de protección (sector público y familia). Las prestaciones monetarias tuvieron un amplio apoyo por parte de las organizaciones de afectados y las familias en la medida en que facilitaban cómo gestionar su destino. Ello se completa, para garantizar la sostenibilidad financiera, con formas de copago (ya que las prestaciones son topadas) y el desarrollo de servicios comunitarios.

Siguiendo la senda de la mayoría de los países de la UE Austria (Óesterle y Heitzman, 2009; Da Roit, Le Bihan y Österle, 2007) ha extendido este sistema de apoyo a los cuidados familiares mediante la regulación de la ayuda doméstica de 24 horas (regularización de las cuidadoras irregulares inmigrantes) en 2007, que sustituye a la mujer trabajadora austriaca o a la familia que no puede hacerse cargo de los cuidados. Esta extensión de la responsabilidad familiar mediante delegación (que representamos en el Gráfico 1), va acompañada de nuevas prestaciones monetarias financiadas por la Seguridad Social.

En el campo de los servicios sociales provinciales y locales la externalización de servicios y la sustitución de las ONG por las empresas privadas son rasgos que también caracterizan al modelo austriaco.

El modelo alemán de 1995, en general más conocido que el anterior a pesar de que fue el segundo en ponerse en marcha, es un modelo de cobertura universal al que se accede previa valoración técnica que clasifica a la población en situación de dependencia en tres grados. Quedan excluidos los grupos de alta renta que tienen que acceder obligatoriamente a los seguros privados (en torno al 10 por cien de la población). El reconocimiento de la dependencia es un derecho subjetivo y se materializa en unas prestaciones básicas a elegir por la persona afectada o sus familiares entre servicios y prestaciones monetarias (Schneider y Reyes, 2007). Las prestaciones son topadas y de hecho han estado congeladas entre 1995 y 2008 por lo que la diferencia del coste entre las prestaciones y, en su caso, los servicios, ha sido asumido por las personas dependientes, sus familias o los municipios a través de los recursos de la asistencia social. Las prestaciones básicas son financiadas si bien la prestación de servicios sociales por los municipios se realiza también mediante impuestos generales y recursos propios.

El modelo alemán de CLD está dirigido a reforzar los cuidados familiares. Los cuidadores familiares están integrados en la Seguridad Social y hacen del trabajo de cuidados carrera de seguro. Las excedencias del trabajo por razón de los cuidados también forman parte del sistema. Pero al mismo tiempo este sistema se refuerza con la libertad de elección entre tipos de prestaciones y la lógica de mercado también se refuerza mediante la elección de proveedores. No es casual que la oferta no lucrativa 
de servicios sociales, casi única hace veinte años, haya sido en gran medida sustituida por el sector mercantil. De este modo la intervención histórica en los CLD de las esferas estatal, familiar y ONG ha provocado la ampliación del sector mercantil, el retroceso de las ONG, el reforzamiento de la familia y la contención del Estado.

Finalmente cabe mencionar el modelo francés (Le Bihan y Martin, 2007) como un modelo que, después de un primer ensayo fallido de CLD de tipo asistencial a finales de la década de los 90 (1997: Prestation spécifique dépendence), pone en marcha en 2002 un sistema de cobertura universal basado en la llamada prestación de CLD (allocation personnalisée à l,autonomie o APA) y en deducciones fiscales para los que emplean cuidadores a domicilio. Este sistema cubre a la población mayor de 60 en situación de dependencia reconocida. Como todos los modelos continentales, y también el español, es un modelo mixto que interrelaciona las diferentes esferas de bienestar: el Estado amplía su esfera mediante la universalización de prestaciones, la familia se refuerza para continuar por otros medios en sus obligaciones tradicionales y el mercado amplía su espacio en la prestación de servicios y en los seguros privados. Como en otros modelos la prioridad de la política de los CLD se centra en los cuidados domiciliarios y en la libertad de la persona afectada o sus familiares para organizar los cuidados. La atención informal es el núcleo central del sistema que se reconstruye y refuerza mediante el APA y las desgravaciones fiscales y que tiene sus raíces en la obligación legal de alimentos. De este modo también se contienen los costes del sistema de dependencia y se refuerza la responsabilidad familiar y la centralidad del tiempo informal de cuidados.

A la prestación de dependencia (APA) se accede mediante la valoración de la dependencia (escala AGGIR de seis niveles, la dependencia tiene su nivel más grave en el nivel 1 y la entrada en el sistema se produce en el nivel 4). La prestación es asignada por un equipo profesional con la intervención de la familia que puede elegir atención profesional o mediante familiares, en todo caso controlado por los servicios sociales. Las prestaciones asignadas son topadas y existe el copago en función de la renta.

El modelo francés, como los modelos centrados en la atención familiar, afronta en el futuro la escasez de cuidadores familiares, las tensiones que provoca la conciliación entre cuidados y trabajo en el mercado ordinario y la extensión de nuevas discapacidades de tipo cognitivo que son altamente invalidantes y costosas en cuanto a cuidados. En este sentido la consolidación del llamado quinto riesgo (los otros son sanidad, pensiones, familia y accidentes laborales), el de dependencia, está aún sometido a los problemas de sostenibilidad financiera y a la articulación de las esferas estatal, familiar y mercantil.

4. Finalmente, en cuanto al régimen mediterráneo de CLD, nos referiremos a los casos de Italia y España al tratarse de sistemas de dependencia en proceso de extensión (Italia) o de cambio de modelo (España).

Italia como España son dos modelos de Estado de Bienestar en los que los cuidados a personas en situación de dependencia han estado, y siguen estando a cargo de las familias (las mujeres en particular). Han sido caracterizados como regímenes de bienestar "familísticos". Siendo totalmente cierto no podemos olvidar, caso de los 
países del régimen continental, que no es un rasgo exclusivo de los países del Sur de Europa.

El modelo tradicional de atención a la dependencia se centraba en la familia, subsidiariamente el Estado vía asistencial y complementado con la intervención de organizaciones voluntarias y religiosas. En los dos últimos veinticinco años este modelo se ha visto sometido a un profundo contraste con la aceleración de los cambios sociodemográficos y culturales $\mathrm{o}$, si se prefiere, una profunda tensión entre una tradición de cuidados inviable a largo plazo y, por otra parte, los cambios sociales internos y la influencia de las políticas europeas de CLD.

El caso italiano parte de un sistema de cuidados como el antes mencionado y a partir del mismo reconstruye y amplia un sistema familiar de CLD ampliando progresivamente un sistema asistencial que no ha concluido aún en otro de tipo universal. Ya en 1980 se aprueba una prestación por ayuda de tercera persona para personas con grave discapacidad menores de 65 años (indemnità di accompagnamento) financiado por la Seguridad Social. El proceso de envejecimiento de la población extiende en 1988 dicha prestación monetaria a la población mayor de 65 años. Desde entonces la extensión de la cobertura de una prestación fija, sin modular por grados y niveles de dependencia, ha sido imparable entre los mayores de 65 años hasta el punto de que de los casi 1,7 millones de perceptores en 2007 el 57 por cien tenía 80 y más años y la población mayor de 65 años era el 83 por cien del total de beneficiarios. Esta extensión asistencial de la prestación (472 euros en 2009) es un sistema de compensación del cuidado informal y un medio también para remunerar a las empleadas domésticas, en su mayoría mujeres inmigrantes e, incluso, para financiar parte del coste de los servicios formales públicos o privados.

El modelo italiano completa su cobertura asistencial con los servicios sociales municipales y regionales, de base asistencial, externalizados hacia empresas y ONG y mediante una extensa delegación de los cuidados a las mujeres inmigrantes por parte de las familias y las mujeres trabajadoras (sin pérdida de control de la organización interna de los cuidados) (Bettio y otros, 2006); es el llamado bienestar encubierto a partir de un nuevo proletariado de servicios domésticos, una parte del cual está regularizado y otra parte en situación irregular, tal como sucede en parte en el caso español.

Se trata, en todo caso, de un modelo en proceso de cambio pero sin reformas profundas (Pavolini y Ranci, 2008; Naldini y Saraceno, 2008). La paradoja del modelo italiano es que habiendo logrado un notable grado de cobertura mediante la prestación monetaria única de dependencia (el 24 por cien de la población mayor de 65 años) y un gasto público importante en esta prestación, más de medio punto porcentual del PIB, no ha dado el salto hacia un modelo universal con regulación única, modulado en grados de dependencia y basado en un sistema cooperativo de gobierno. Es decir, se trata de una arquitectura incompleta en la que el problema fundamental es la coordinación efectiva entre la administración central y las regiones y municipios y entre estos dos últimos niveles de gobierno en los que, a diferencia del caso español, son los municipios los que disponen de los recursos. 
Finalmente y en relación con el caso español destacaremos de manera sucinta sus rasgos fundamentales remitiéndonos a la amplia bibliografía existente de la que mencionamos algunos textos (Casado, 2004; Defensor del Pueblo, 2000; Cobo Gálvez, 2009; Fantova, 2008; Marbán, 2009; Montserrat Codorniu, 2005 y 2009; Navarro, 2005 y 2007; Rodríguez Cabrero, 2004 y 2007; Rodríguez Rodríguez, 2006; Sarasa, 2003; Vilá, 2009; Grupo de Expertos, 2009).

Hasta finales de la década de los años 80 del pasado siglo la atención a las situaciones de dependencia tenía una doble respuesta: a) por una parte la Seguridad Social mediante la pensión de gran invalidez que establece un complemento por ayuda de tercera persona equivalente al 50 por cien de la pensión para todos aquellos que antes de la edad de jubilación hubieran tenido un accidente laboral grave; este complemento se extiende al nivel no contributivo en 1982 para las personas con discapacidad y se perfecciona con la ley de prestaciones no contributivas de 1990 para las personas con elevado grado de discapacidad que les impide realizar actividades de la vida diaria; b) por otra parte, el sistema de servicios sociales de los Municipios, Diputaciones y Comunidades Autónomas, con una oferta de servicios comunitarios y residenciales para personas con necesidad de ayuda orientado progresivamente a toda la población pero bajo criterios de entrada de tipo asistencial. Se puede afirmar que, aproximadamente, es en 1992, con la aprobación del Plan Gerontológico Estatal, cuando el debate sobre el impacto del envejecimiento empieza a tomar cuerpo. Más que el impacto económico e institucional lo que dicho Plan pone de manifiesto es que estaban empezando a madurar con gran rapidez los factores sociales y políticos asociados al envejecimiento de la población en conexión profunda con cambios familiares y una profunda revolución de género. Los cuidados personales salen a luz progresivamente poniendo de manifiesto la carga que suponen en términos de tiempo, costes de oportunidad y relaciones sociales truncadas por dicha actividad; también la dimensión positiva que ellos suponen para las personas afectadas y los propios cuidadores. De lo que se trataba era de poner de manifiesto que la carga de cuidados es una función de reproducción que requiere el reconocimiento de su existencia social como paso previo a su reconocimiento y posterior adopción de formas de socialización. Después de un largo período de debate, acuerdos sociales y demandas en seno del Pacto de Toledo (2003), la publicación del Libro Blanco de la Dependencia en 2005 inicia una senda de debate político de casi dos años, que concluye el 30 de noviembre de 2006 con la aprobación de la ley de promoción de la autonomía personal y atención a las personas en situación de dependencia (LAPAD).

El sistema español es un modelo complejo de CLD que responde y es influido por la nueva generación de derechos sociales que está emergiendo en la EU, donde la cobertura del riesgo se comparte entre varios agentes institucionales y sociales, afectados y cuidadores familiares; se garantiza una cobertura universal en base a prestaciones básicas topadas; se gestiona de manera descentralizada; la provisión de servicios es mixta en un marco de fuerte competencia entre los sectores mercantil y sin fin de lucro; y canaliza las reivindicaciones y demandas sociales mediante un amplio sistema de participación de los agentes sociales y económicos y las ONG en varios sistemas consultivos. En suma, se trata de un sistema de protección social universal 
pero sometido a reglas de cooperación, contenido financieramente y sometido a un cierto grado de racionalización y coordinación institucional. Todo lo cual ha dado pie a tensiones institucionales y financieras en su puesta en marcha. Por otra parte, no podemos olvidar que se trata de una nueva extensión del Estado de Bienestar que contribuye a reforzar el sistema de protección social en su conjunto (Comín Comín, 2008) en un contexto no precisamente favorable que conlleva su racionalización y contención (Álvarez, S. y Guillén, A. (2004).

El diseño del modelo español es un mix entre el modelo nórdico (cobertura universal, financiación con impuestos - también cotizaciones - y orientado por norma a los servicios sociales) y el continental (regulación estatal de la valoración de la dependencia, garantía de igualdad en el ejercicio del derecho subjetivo mediante prestaciones básicas por la Administración Central, valoración de la dependencia por grados y niveles, importancia de la libre elección de las personas afectadas y sus familias, Seguridad Social del cuidador no profesional, descentralización en las CCAA de la planificación y gestión), a los que en cierto modo ha seguido partiendo de la existencia de un conglomerado o rama de atención histórica en el que confluían el sistema sanitario, los servicios sociales y las prestaciones de la Seguridad Social. Es decir, se ha desarrollado en estos dos años un modelo de CLD de amplia y creciente cobertura, con amplios diferencias en algunas CCAA, preferencia por las prestaciones económicas respecto de los servicios (AEDGSS, 2009), (en lo que sin duda ha influido una oferta de servicios que es aun insuficiente a pesar de su notable crecimiento en los últimos veinte años y el impacto de la crisis económica y financiera), que se dividen mitad por mitad el volumen de prestaciones sociales, un modelo de gobernanza o de cooperación entre Administración Central y Autonómica relativamente estable, después de las tensiones y ajustes iniciales de su puesta en marcha, con un papel subordinado de las corporaciones locales.

En 2010 está teniendo lugar la evaluación institucional del SAAD, prevista en la ley. A la espera de sus resultados, varios efectos cabe señalar en el desarrollo de la misma: una extensión de la cobertura que alcanza a 650.000 personas de los Grados III y II de dependencia; el crecimiento de unos cien mil nuevos empleos directos en servicios sociales sin considerar los empleos inducidos vía prestaciones económicas, cuyas condiciones de trabajo son objeto de análisis sindical (Comisiones Obreras, 2008); un reforzamiento del sistema regional y municipal de servicios sociales que parece transitar desde un modelo asistencial a otro mixto; un crecimiento de la oferta privada mercantil en los servicios sociales que consolida un desarrollo iniciado en la década de los $90 \mathrm{y}$, junto a ello, nuevas ofertas del sector privado que promueven seguros complementarios para grupos de renta elevada.

La pregunta que cabe plantear es si el modelo español, como otros modelos de CLD, es una respuesta de socialización del riesgo cuya consecuencia no buscada es la reconstrucción del tradicional sistemas de cuidados informal y, por tanto, la preservación de prácticas sociales que hacen recaer sobre la mujer el grueso de la carga de cuidados. La confluencia de las preferencias sociales, la contención de costes en el Estado de Bienestar y las permanencia y revitalización de visiones e ideologías conservadoras (Guillén, 2010) y neoliberales en el Estado de Bienestar pueden estar 
contribuyendo a que esta rama de protección social alcance unos niveles limitados de institucionalización.

\section{Cuadro 2}

\section{Reformas en los modelos europeos de cuidados de larga duración}

\begin{tabular}{|c|c|c|c|c|}
\hline $\begin{array}{l}\text { REFORMAS DEL } \\
\underline{\text { PERÍODO }} \\
\underline{1980-2000}\end{array}$ & $\begin{array}{l}\text { Modelo anglosajón } \\
\text { (Reino Unido, } \\
\text { Irlanda) }\end{array}$ & $\begin{array}{l}\text { Modelo continental } \\
\text { (Alemania, Francia, } \\
\text { Austria, Holanda, } \\
\text { Luxemburgo, Bélgica) }\end{array}$ & $\begin{array}{l}\text { Modelo nórdico } \\
\text { (Suecia, Finlandia, } \\
\text { Dinamarca) }\end{array}$ & $\begin{array}{l}\text { Modelo mediterráneo } \\
\text { (España, Italia, } \\
\text { Portugal, ) }\end{array}$ \\
\hline $\begin{array}{l}\text { Derecho social a la } \\
\text { protección social de } \\
\text { la dependencia }\end{array}$ & $\begin{array}{l}\text { Derecho mixto: } \\
\text { universal en } \\
\text { atención sanitaria y } \\
\text { protección asisten- } \\
\text { cial en servicios } \\
\text { sociales }\end{array}$ & $\begin{array}{l}\text { Derecho universal con } \\
\text { dos niveles: contribu- } \\
\text { tivo y no contributivo }\end{array}$ & Derecho universal & $\begin{array}{l}\text { Derecho mixto: } \\
\text { universal en atención } \\
\text { sanitaria; asistencial } \\
\text { en servicios sociales }\end{array}$ \\
\hline Financiación & $\begin{array}{l}\text { Impuestos y copago } \\
\text { en servicios } \\
\text { sociales para los } \\
\text { que exceden un } \\
\text { nivel de renta }\end{array}$ & $\begin{array}{l}\text { Cotizaciones en el } \\
\text { nivel contributivo; } \\
\text { impuestos en el nivel } \\
\text { no contributivo; } \\
\text { copago en la presta- } \\
\text { ción de servicios. }\end{array}$ & $\begin{array}{l}\text { Impuestos generales y } \\
\text { locales; copago }\end{array}$ & $\begin{array}{l}\text { Impuestos generales, } \\
\text { cotizaciones y copago } \\
\text { para los que exceden } \\
\text { un nivel de renta }\end{array}$ \\
\hline Prestaciones sociales & $\begin{array}{l}\text { Servicios y ayudas } \\
\text { monetarias. Ayudas } \\
\text { técnicas }\end{array}$ & $\begin{array}{l}\text { Servicios y prestacio- } \\
\text { nes monetarias } \\
\text { topadas. Ayudas } \\
\text { técnicas }\end{array}$ & $\begin{array}{l}\text { Servicios sociales y } \\
\text { ayudas técnicas }\end{array}$ & $\begin{array}{l}\text { Prestaciones } \\
\text { monetarias, servicios } \\
\text { asociales y ayudas } \\
\text { técnicas }\end{array}$ \\
\hline $\begin{array}{l}\text { Responsabilidad de } \\
\text { organización y } \\
\text { gestión }\end{array}$ & Municipal & $\begin{array}{l}\text { Seguridad Social, } \\
\text { Regiones y Munici- } \\
\text { pios }\end{array}$ & Municipal & Regional y Municipal \\
\hline $\begin{array}{l}\text { Provisión de } \\
\text { servicios según } \\
\text { importancia }\end{array}$ & $\begin{array}{l}\text { Empresas, ONGs y } \\
\text { ayuntamientos }\end{array}$ & $\begin{array}{l}\text { ONGs y empresas, } \\
\text { papel residual de } \\
\text { ayuntamientos en } \\
\text { modelo alemán }\end{array}$ & $\begin{array}{l}\text { Ayuntamientos y } \\
\text { creciente importancia } \\
\text { de empresas }\end{array}$ & $\begin{array}{l}\text { Ayuntamientos, ONGs } \\
\text { y creciente importan- } \\
\text { cia de empresas }\end{array}$ \\
\hline $\begin{array}{l}\text { Políticas de apoyo al } \\
\text { cuidado informal }\end{array}$ & $\begin{array}{l}\text { Apoyo limitado al } \\
\text { cuidador y elevada } \\
\text { responsabilidad } \\
\text { individual }\end{array}$ & $\begin{array}{l}\text { Amplio apoyo al } \\
\text { cuidador informal }\end{array}$ & $\begin{array}{l}\text { Apoya y sustituye a la } \\
\text { familia cuidadora }\end{array}$ & $\begin{array}{l}\text { Limitado apoyo al } \\
\text { cuidador informal }\end{array}$ \\
\hline $\begin{array}{l}\text { Situación actual de } \\
\text { los modelos }\end{array}$ & $\begin{array}{l}\text { Debate político } \\
\text { sobre la oportuni- } \\
\text { dad de la universa- } \\
\text { lización de la } \\
\text { protección social de } \\
\text { la dependencia }\end{array}$ & $\begin{array}{l}\text { Reformas en Alemania } \\
\text { en } 2007 \text { para lograr } \\
\text { nuevos equilibrios } \\
\text { institucionales y } \\
\text { financieros del } \\
\text { modelo. Reformas } \\
\text { previstas en Holanda }\end{array}$ & $\begin{array}{l}\text { Incremento de la } \\
\text { prestación de servicios } \\
\text { por parte de las } \\
\text { empresas privadas en } \\
\text { Suecia y, en general, } \\
\text { en los países nórdicos }\end{array}$ & $\begin{array}{l}\text { Aprobación de la ley } \\
\text { de la dependencia en } \\
\text { España. Libro Blanco } \\
\text { de la dependencia en } \\
\text { Italia. }\end{array}$ \\
\hline \multicolumn{5}{|l|}{$\begin{array}{l}\text { REFORMAS } \\
\underline{2000-2010}\end{array}$} \\
\hline $\begin{array}{l}\text { Principios } \\
\text { orientadores }\end{array}$ & $\begin{array}{l}\text { Consumerismo } \\
\text { individualización } \\
\text { del riesgo }\end{array}$ & $\begin{array}{l}\text { Refamiliarización y } \\
\text { mercantilización }\end{array}$ & $\begin{array}{l}\text { Universalización, } \\
\text { familiarización y } \\
\text { mercantilización dual }\end{array}$ & $\begin{array}{l}\text { Universalismo, } \\
\text { familiarización y } \\
\text { mercantilización }\end{array}$ \\
\hline Accesibilidad & $\begin{array}{l}\text { Preferencia } \\
\text { personas en gave } \\
\text { dependencia sin } \\
\text { recursos }\end{array}$ & Universal & Universal & $\begin{array}{l}\text { Transición hacia } \\
\text { cobertura universal }\end{array}$ \\
\hline
\end{tabular}




\begin{tabular}{|l|l|l|l|l|}
\hline Prestaciones & $\begin{array}{l}\text { Preferencias } \\
\text { prestaciones } \\
\text { monetarias y } \\
\text { presupuesto } \\
\text { personal }\end{array}$ & $\begin{array}{l}\text { Preferencia prestacio- } \\
\text { nes monetarias y } \\
\text { programas concilia- } \\
\text { ción }\end{array}$ & $\begin{array}{l}\text { Servicios: crecimiento } \\
\text { prestaciones moneta- } \\
\text { rias y presupuesto } \\
\text { personal }\end{array}$ & $\begin{array}{l}\text { Preferencia prestacio- } \\
\text { nes monetarias; } \\
\text { servicios sociales } \\
\text { municipales y } \\
\text { regionales }\end{array}$ \\
\hline Provisión & Privada mercantil & $\begin{array}{l}\text { Privada: mercantil; } \\
\text { tercer sector en declive }\end{array}$ & $\begin{array}{l}\text { Pública con crecimien- } \\
\text { to sector mercantil }\end{array}$ & $\begin{array}{l}\text { Mixta: provisión tercer } \\
\text { sector y crecimiento } \\
\text { sector mercantil }\end{array}$ \\
\hline Financiación & $\begin{array}{l}\text { Mixta: pública y } \\
\text { copago }\end{array}$ & $\begin{array}{l}\text { Mixta: impuestos, } \\
\text { cotizaciones y copago }\end{array}$ & Pública y copago & $\begin{array}{l}\text { Mixta: impuestos y } \\
\text { copago. También } \\
\text { cotizaciones }\end{array}$ \\
\hline Gobernanza & $\begin{array}{l}\text { Fragmentación } \\
\text { institucional y } \\
\text { regulación central }\end{array}$ & $\begin{array}{l}\text { Regulación central y } \\
\text { gestión regional con } \\
\text { financiación } \\
\text { compartida }\end{array}$ & $\begin{array}{l}\text { Regulación central y } \\
\text { gestión municipal }\end{array}$ & $\begin{array}{l}\text { Fragmentación con } \\
\text { tendencia a sistemati- } \\
\text { zación }\end{array}$ \\
\hline
\end{tabular}

Fuente: Elaboración propia en base a: Gledinning (2007)Huber (2009); Pommer, Weittiez y Stevens (2007); OCDE (2005)

\section{Conclusiones}

La atención a las situaciones de dependencia y apoyo a la autonomía de las personas se ha convertido en los últimos años en una nueva rama de protección social junto al sistema de pensiones y el sistema sanitario. Esta extensión del Estado de Bienestar ha tenido lugar, en general, bajo contextos complejos de reestructuración de este modelo lo que ha supuesto formas variadas de recalibración (o reequilibrios internos en el entramado institucional), políticas de contención de costes y desplazamiento hacia el mercado, la familia y los individuos de parte de los riesgos sociales).

En este trabajo hemos puestos de manifiesto cómo los CLD siguen centrándose en los cuidados de la mujer en el seno de los hogares. En torno a éstos las distintas esferas de bienestar, Estado, mercado, tercer sector, intervienen en mayor o menor medida y ello depende de las tradiciones y culturas, del proceso político y de las ideologías que pugnan por dominar la construcción social del bienestar.

Con la excepción del régimen nórdico de bienestar, el modelo dominante de CLD entre 1950 y 1980, en los regímenes de bienestar bismarkiano y del Sur de Europa, se basaba en la centralidad de la familia, la subsidiaridad del Estado y la residualidad del mercado. En el modelo anglosajón también tenía lugar una combinación entre atención asistencial y el papel de la familia. La confluencia en el tiempo de la crisis del Estado de Bienestar, el envejecimiento de la población y cambios sociodemográficos profundos (trabajo de la mujer en el mercado ordinario y de los roles familiares de cuidados), junto a la maduración ideológica del consumerismo y el ascenso de las ideologías pro mercado, han conducido a la mayoría de los Estados de Bienestar a construir modelos sui géneris que establecen combinaciones específicas de socialización del riesgo, refamiliarización y creciente responsabilidad individual frente al riesgo.

Si la socialización se hacía en parte inevitable como respuesta al cambio social y económico no por ello tenía que ser intensa, ni podía serlo, dado el peso de las tradiciones de cuidados en la familia y la lentitud en la construcción de una división social 
nueva de género en los cuidados. Pero, además, la socialización venía limitada desde el origen por las propias exigencias de reestructuración del Estado de Bienestar (contención del gasto social) y las presiones del mercado que encuentra en este campo de necesidades una oportunidad de rentabilidad mediante la transformación parcial de los cuidados en mercancía.

Al ser los CLD la última rama de protección social en adquirir un cierto nivel de institucionalización bajo los constreñimientos señalados, acelerados en la actualidad con la crisis económica y financiera, se abre un espacio de incertidumbres sobre su desarrollo futuro que, en todo caso, va unido inexorablemente al futuro del sistema de pensiones y del sistema de salud. En este sentido el avance en la igualdad social que supone el desarrollo de los nuevos sistemas de cobertura universal de CLD, con todos los condicionamientos señalados, arroja sombras sobre el futuro de la misma. Cabe pensar razonablemente a la luz del desarrollo de las reformas que han tenido lugar desde la segunda mitad de la presente década que los avances en la socialización del riesgo se verán frenados o, al menos, condicionados por nuevas formas de refamiliarización, mercantilización e individualización del riesgo.

\section{Bibliografía}

Abellán, A. Esparza, C. (2006). Las personas mayores con dependencia. En R.Puyol y A. Abellán ( coor.) Envejecimiento y dependencia. Madrid: Mondial Assistance.

Adelantado, J. et Calderón, E. (2005). Globalización y Estados de Bienestar: ¿respuestas semejantes a problemas parecidos. Cuadernos de Relaciones Laborales, $\mathrm{n}^{\mathrm{o}} 2,2005$.

Alonso Benito, L.E. (2009) (2009). Crítica del posmodernismo liberal. Madrid: Libros de la Catarata.

Arriba, A y Moreno, J. (edi.) (2009). El tratamiento de la dependencia en los regímenes de bienestar europeos contemporáneos. Madrid: IMSERSO.

Álvarez, S. y Guillén, A. (2004). The OECD and the Reformulation of Spanish Social Policy: a combined search for expansion and rationalization. In K. Armingeon and M. Beleyer (eds.): The OECD and European Welfare States. Chetelham: Edward Elgar

Asociación Estatal de Directoras y Gerentes en Servicios Sociales (AEDGSS) (2009). "Desarrollo e implantación territorial de la Ley de Promoción de la Autonomía Personal y Atención a las Personas en Situación de Dependencia”; III Dictamen, (http://www.directoressociales.com/).

Blomquist, P. (2004). The choice revolution: privatization of Swedish Welfare Services in the 1009s". Social Polícy Administration, volume 38, $\mathrm{n}^{\circ} 2$. 
Bettio, F. et al. (2006). Change in Care Regimes and Female Migration: The Care Drain in the Mediterranean. Journal of European Social Policy, 16(3): 271-285.

Bond, J y Rodríguez Cabrero, G. (2007). Health and dependency in later life. En J.Bond and S.Peace (Edited): Ageing and Society. London: Sage.

Bonoli, G. (2005). The politics of the New Social Policies: providing coverage against new social risks in Mature Welfare. Policy \& Politics, 33 (3).

Casado, D. (dir.) (2004). Respuestas a la dependencia, Madrid, CCS.

Casas Mínguez, F. (2010). Los servicios sociales y el mercado de servicios en la Unión Europea. En Rodríguez Cabrero, G (Coor.): Servicios sociales y cohesión Social. Madrid: CES.

Cobo Gálvez, P. (2009). Génesis y elaboración de la Ley de promoción de la Autonomía y Atención a las personas en situación de dependencia. Documentación Administrativa, $n^{\circ}$ 276-27. Monográfico sobre El sistema para la autonomía y la atención a la dependencia.

Colombo, F., Fujisawa, R., Llena, A., Pearson, M. (2009). La necesidad creciente de trabajadores para cuidados de larga duración (CLD). ¿Qué están haciendo los países de la OCDE? Revista Economistas, $\mathrm{n}^{0} 122$.

Comín Comín, F. (2008). La protección social en la democracia (1977-2008). En

Castillo, S. (Ed) (2008) Solidaridad, seguridad, bienestar. Cien años de protección social en España. Madrid: Ministerio de Trabajo e Inmigración.

Comisiones Obreras (2008). El empleo en la atención a la dependencia. Hacia un sector productivo de calidad. Madrid: Confederación Sindical de CCOO.

CONSEJO DE EUROPA (1998). Recomendación $N^{o} R$ (98) 9 del Comité de Ministros a los estados Miembros relativa a la dependencia.

CONSEJO Y COMISIÓN EUROPEOS (2003). Apoyar las estrategias nacionales para el futuro de la asistencia sanitaria y los cuidados a las personas mayores., Bruselas, Comisión Europea.

Da Roit, B, Le Bihan, B., Ósterle, A. (2007). Long-term care policies in Italy, Austria and France : variations in cash-for-care schemes. Social Policy \& Administration, vol. $41, \mathrm{n}^{\circ} 6$.

Dahl, H.M. (2009). New public management, care and struggles about recognition. Critical Social Policy, 29 (4).

Daly, M. (2003). El trabajo asistencial. En busca de la seguridad. Madrid: MTAS.

DEFENSOR DEL PUEBLO (2000). La atención sociosanitaria en España: perspectiva gerontológica y otros aspectos conexos. Madrid, Defensor del Pueblo. 
Del Pino, E. (2009). Un marco conceptual para el studio del cambio del Estado de Bienestar y las políticas sociales. En L.Moreno (2009) Reformas de las políticas de bienestar en España. Madrid: Siglo XXI.

Duran Heras, M ${ }^{\mathrm{a}}$ A. (2000). Los costes invisibles de la enfermedad. Madrid: Fundación BBVA.

Esping-Andersen, G. (1990). The three worlds of welfare capitalism, Cambridge: Polity.

Fantova, F. (2008). "Sistemas públicos de servicios sociales. Nuevos derechos, nuevas respuestas". Bilbao: Instituto de Derechos Humanos (Universidad de Deusto).

Ferrera, M. \& Rodhes, M. (Eds.) (2000). Recasting European Welfare Status. London: Frank Cass

Guillen, A.M. (2010). Desfrosting the Spanish Welfare State: the weithgt of conservative components. In Palier, B. (ed): A long Good Bye to Bismark: the politics of welfare reform in continental Europe. Amsterdam: Amsterdam University Press.

Huber, M., Hennessy, P., Izuni, J., Kim, W. \& Lunsgaard, J. (2005). Long-term care for older people. Paris: OCDE.

Huber, M., Rodrigues, R., Hoffmann, F., Gasior, K, Marin, B. (2009). Facts and figures on Long-term care: Europe and North America. European centre for Social Welafare Policy and Research. Viena..

IMSERSO (2005). Libro Blanco: Atención a las Personas en situación de dependencia en España, Madrid, Imserso.

Le Bihan, B. y Martin, C. (2007). Cash for care in the French welfare state: a skilful compromise?. En En Urgenson, C. y Yeandle, S. (eds) Cash for care in developed welfare states. Houndmills: Plagrave MacMillan.

Ley 39/2006, de 14 de diciembre, de Promoción de la Autonomía Personal y Atención a las personas en situación de dependencia.

Lundsgaard, J. (2005). Consumer direction and choice in long-term care for older persons, including payments for informal care: how can it help improve care outcomes, employments and fiscal sostenibility. Health Working Paper, vol. 20.Paris: OECD.

Marban, V. (2009). La atención a la dependencia. En L.Moreno (edi) Reformas de las políticas de bienestar en España. Madrid: Siglo XXI.

Martínez Buján, R. (2010). Bienestar y cuidados: el oficio del cariño. Mujeres inmigrantes y mayores nativos, Madrid: CSIC.

Means, R., Morbey, H. y Smith, R. (2002). From community care to market care?. The development of welfare services for older people. Bristol: The Polity Press. 
Monserrat Codorniu, J (2005). El reto de un sistema universal de protección a la dependencia: una estimación del coste del modelo, Presupuesto y Gasto Público, $n^{\circ} 39 / 2005$.

Montserrat Codorniu, J. (2009). Evolución y perspectivas de la financiación del sistema para la autonomía y atención a la dependencia. Documentación Administrativa $\mathrm{n}^{\circ}$ 276/277.

Moreno, L. (ed.) (2009). Reformas de las políticas de bienestar en España. Madrid: Siglo XXI.

Naldini, M. y Saraceno, C. (2008). Social and familia policies in Italy: not totally frozen but far from structural reforms. Social policy \% Administration, vo. 42, 2.

Navarro, V. (2005). La situación social en España I. Madrid, Biblioteca Nueva.

Navarro, V. dir. (2007). La situación social de España. Madrid: Biblioteca Nueva.

OECD (2005). Ensuring quality long-term care for older people. Policy Brief, vol march 2005. Paris: OECD.

Óesterle, A. y Heitzman, K. (2009). Welfare State development in Austria: strong traditions meet new challenges. En Schubert, K., Hegelich, S., Bazant, U. (eds) The handbook of European Welfare Systems. London: Routledge.

Pacolet, J. (2006). "Protección social de personas mayores dependientes: sostenibilidad del Estado de Bienestar y ámbito del seguro de cuidados de larga duración”. Revista Española del Tercer Sector, nº 3, Mayo-Agosto.

Pavolini, E. and Ranci, C. (2008). "Restructuring the Welfare State: reforms in longterm care in Western European countries". Journal of European Social Policy, volume $18, \mathrm{n}^{\mathrm{o}} 3$.

Rodríguez Cabrero, G. (2004). Protección social de la dependencia en España. Documento de Trabajo 44/2004, Madrid, Fundación Alternativas.-

Rodríguez Cabrero, G. (2005). Modelos de Protección Social a la Dependencia con especial referencia al espacio europeo. En V. Navarro (dir.) La situación social en España, Madrid, Biblioteca Nueva

Rodríguez Cabrero, G. (2007, a). "La protección social de la dependencia en España.Un modelo sui generis de desarrollo de los derechos sociales". Política y Sociedad no 4 (vol. 44).

Rodríguez Cabrero, G. (2009). "El desarrollo de la política social de promoción de la autonomía y atención a las personas en situación de dependencia en España (20072009)", Gestión y Análisis de Políticas Públicas, n 2, julio-diciembre 2009, pp 33-58. 
Rodríguez Rodríguez, P. (2006). "El sistema de servicios sociales español y las necesidades derivadas de la atención a la dependencia". Madrid: Fundación Alternativas, Documento de Trabajo 87.

Rogero García, J. (2010). "Los tiempos del cuidado. El impacto de la dependencia de los mayores en la vida cotidiana de sus cuidadores". Madrid: IMSERSO.

Rostgaard, T. (2006). Constructing the care consumer: free choice of home care for the elderly in Denmark. European societies, 3 (3).

Sipilä; (ed.) (1997). Social care services: the key to the Scandinavian welfare model. Adershot: Avebury.

Sarasa, S. (2003). Una propuesta de servicios comunitarios de atención a personas mayores. Madrid: Fundación Alternativas.

Schneider, U y Reyes, C. (2007). Mixed blessings: long-term care benefits in Germany. En Urgenson, C. y Yeandle, S. (eds) Cash for care in developed welfare states. Houndmills: Plagrave MacMillan.

Sotelo, H. (2007). Tendencias recientes en los servicios sociales europeos: algunos ejemplos paradigmático. En D. Casado y F. Fantova (coordinadores): Perfeccionamiento de los servicios sociales en España. Madrid: FOESSA.

Schut, F. T. y Van den Berg, B. (2010). Sustainability of comprenhensive universal long-term care insurance in teh Netherlands. Social Policy and Administration, 44 (4).

Taylor-Gooby, P. (2004). (ed.) New Risks, New Welfare. The Transformation of the European Welfare State". Oxford: Oxford University Press.

Vilá, A. (2009). Tendencias de la nueva legislación de los servicios sociales. Madrid: EAPN.

VV.AA. (2009). Informe final del grupo de expertos para la evaluación del desarrollo y efectiva aplicación de la Ley 39/2006 de 14 de diciembre de promoción de la autonomía personal y atención a las personas en situación de dependencia (en línea). http://www.imsersomayores.csic.es 